أثر تطبيق بعض المواد الفنية على المواد الدراسية فى تنمية المستوى التعليمي والتحصيلي لتلاميذ الثلاث صفوف الاول من التعليم الاساسي

د. نسرين أحمد حلمى (*) - (م)

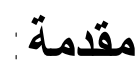

يلعب التعليم الدور الاساسي في بناء شخصية الإنسان و النهوض به ، و التزكيز على التعلم النشط

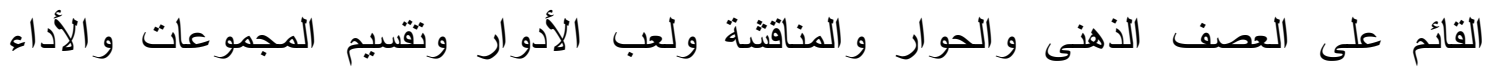

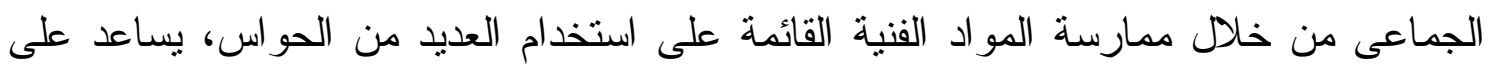

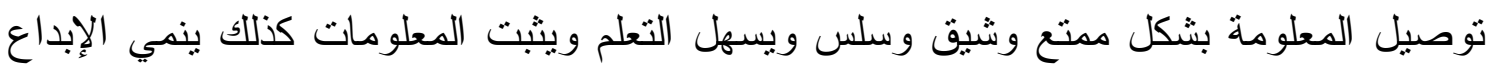

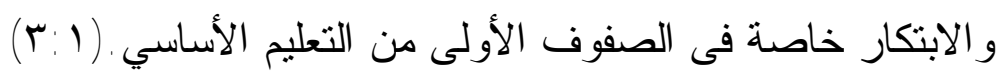

و هنالك ظاهرة أصبحت تفرض نفسها بقوة في السنوات الأخيرة وهي تأخر نطور امكانيات

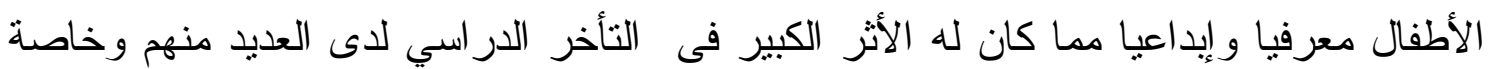
فى السنوات الأولى من التعليم الأساسي ، ويرجع ذلك لعدة أسباب قد يكون منها تأثير البيئة

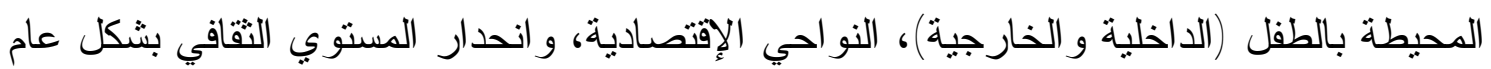

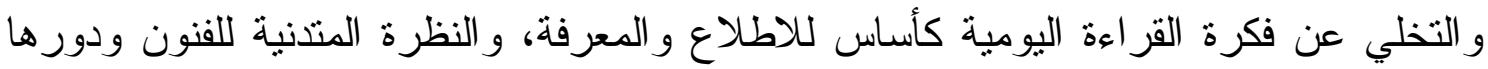
المؤثر و اعتبار ها في العديد من المدارس المصرية كمو اد ثانوية تستخدم فقط للترفيه وبالتالي يتم

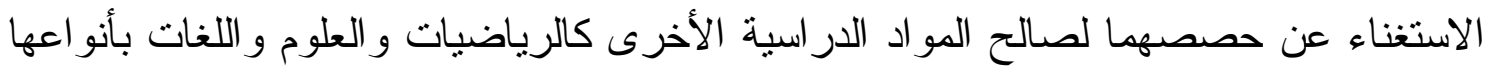
مما جعل العملية التعليمية جافة ومملة.

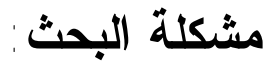

تكمن مشكلة البحث فى ظهور شريحة كبيرة من الأطفال غير قادرين على ممارسة التفكير الإبداعى وبناء المخيلة و الذى انعكس بدوره على انحدار المستوى التحصيلي لديهم ، لذا فكرت

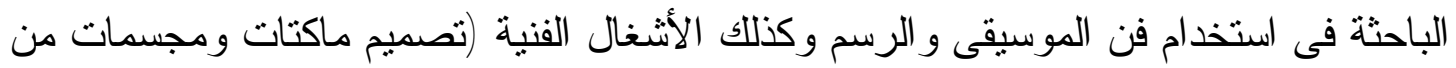

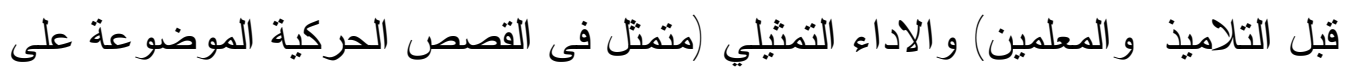
الدروس) لتوضح أثزرها فى تتمية القدر ات الذهنية التى تساعد على سرعة التى الإستيعاب وقوة 
التزكيز و الوصول إلي الإبداع وبناء الوعى الذاتى لدى أطفال الثالاث صفوف الأولي من التعليم

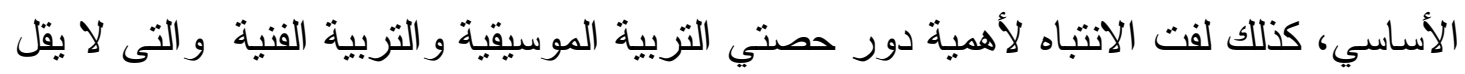
دور هما عن حصص المواد الدراسية الأخرى في النهوض بالعملية التعليمية. أهداف البحث: - 2 - 2

1 - الكثف عن أثزر النطبيق على المواد الدراسية بالمواد الفنية فى تطوير الذكاء المعرفى

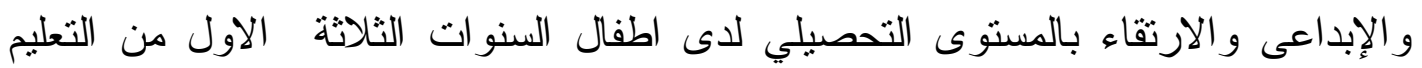

الأساسي.

r - ايجاد طرق علمية لنطوير مهار ات الأطفال فى مجالات الفنون(الموسيقية و الفنبة و الأداء

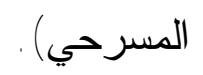

أهمية البحث : تكمن أهمية البحث فى

1 - نطوير الذكاء الإبداعى والفنى لاى الأطفال من خلال ممارستهم لبعض أنواع الفنون

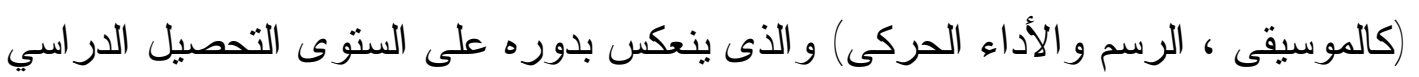

لايهم.

r - نوضيح أهمية توظيف المو اد الفنية(التزبية الموسيقية و التزبية الفنية) فى النطبيق على المو اد

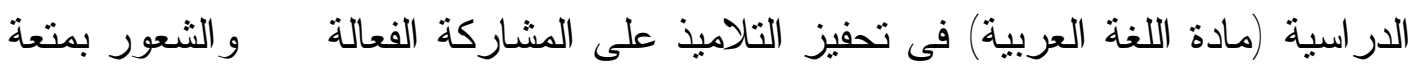

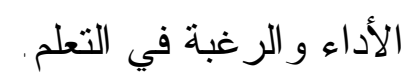

r - تغيير النظرة المتدنية السائدة لتلك المادتين فى المدارس المصرية مما يؤدى الى الحفاظ

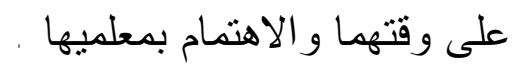
أسئلة البحث: 1 - ما أثر توظيف المواد الفنية (التربية الموسيقية والتربية الفنية) فى التطبيق على المواد

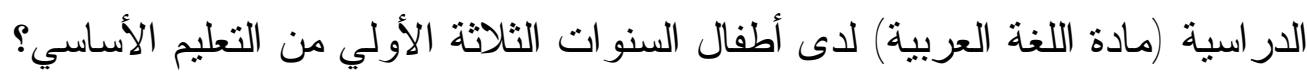
r - ما هى الطرق العلمية لتطوير مهار ات الأطفال فى مجالات الفنون(الموسيقية و الفنية)؟ 


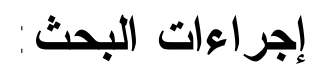

يتبع البحث المنهج التجريبي إستخدام الإختبار القبلى و البعدى .

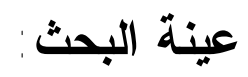

1 - نم اختبار مادتى التربية الموسيقية والتربية الفنية من المواد الفنية'المقدمة بالمدارس

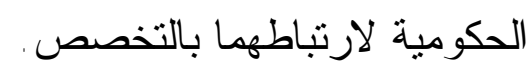

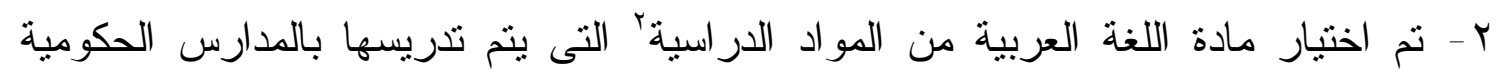
(منهج الثلاث الصفوف الأولي من الكتاب المدرسي). r - نم اختيار العينة من الثلاث صفوف الأولي من التعليم الأساسي. ع تم النطبيق على ثلاث مدارس حكومية فى ثلاث محافظات مختلفة لاستعر اض نتائجهما بالبحث وهما: (مدرسة محمد زهر ان الرسمية لغات بالإسكندرية، مدرسة السلام الرسمية

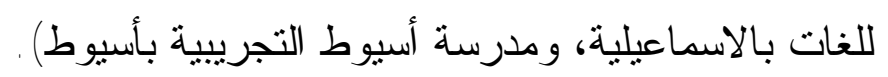

ه تم اعداد المادة العلمية (أناثنيد النحو، القصص الحركية، الألحان، الصور الفنية) من قبل الباحثة وتذريب مدرسين التخصصات الثلاث(المسئولون عن التطبيق داخل الفصول)

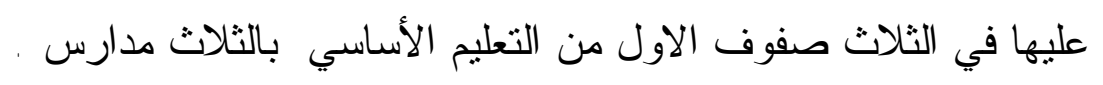

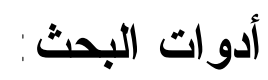

نماذج لاختبار ات قبلية وبعدية، استبيان لفكرة التوظيف و التطبيق من قبل مدرسي اللغة العربية

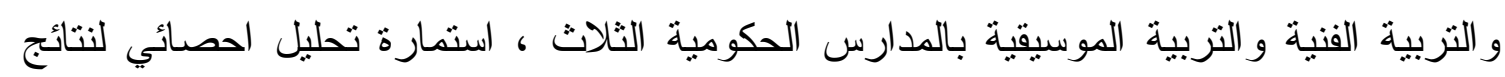
البحث.

ا المو اد الفنية في المدارس المصرية : التربية الموسيقية، النربية الفنبة، النشاط المسرحي، الاقتصاد المنزلي، التصميم الصناعي. r المو اد الدر اسية في المدارس المصرية: اللغات بانو اعها، الرياضيات، العلوم، الدراسات الاجتماعية، المو اد الفلسفية، التربية الدينية و التربية الوطنية. 


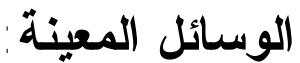

أنانثيد مبتكرة للقو اعد اللغوية ، صور معبرة عن كلمات الأناثيد، قصص حركية تحاكى كلمات الأناثيد المختلفة.

$$
\text { حدود البحث: }
$$

مادة اللغة العربية، الثلات صفوف الأولي للمرحلة الإبتدائية بمحافظة الإسكندرية ، بالية

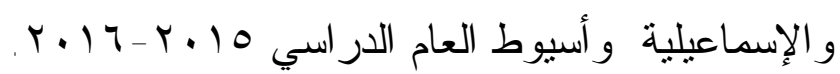

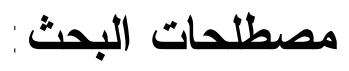

\section{التربية الموسيقية}

مجموعة من العناصر الموسيقية الأساسية (اللحن -الإيقاع - الهارمونى) وفقا لصيغ وقو الب فنية وعلمية محددة وتتثمل القصص الموسيقية الحركية والعزف على الآلات والألعاب الموسيقية

$$
\begin{aligned}
& \text { و التذوق و الغناء. ( ؟ ؛:؟) } \\
& \text { التربية القنية }
\end{aligned}
$$

مجمو عة من المهار ات و الأنشطة الفنية التى يتعرض لها الطفل وتتشمل الرسم ، الأشغال الفنية،

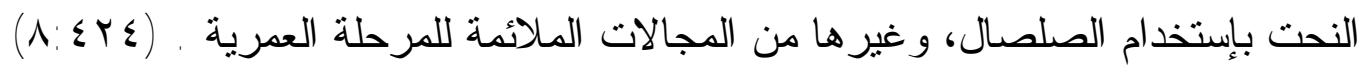
الحصة التقليدية: الحصة الأولي التى يشرح بها معلم اللغة العربية الدرس بطريقته التقليدية قبل توظيف مادتى التزبية الفنية و الموسيقية ويجرى بعدها الإختبار القبلى.

الحصة الثاملة: هى الحصة الثانية لنطبيق الدرس فى مادة اللغة العربية وتاتى بعد الحصة التقليدية و حصنى التزبية الفنبة و التزبية الموسيقية التى يتم التوظيف بهما وتتثمل تمثيل القصص الحركية المؤلفة على موضوع النشيد بالإستعانة بالمجسمات المصممة بالتربية الفنية لنية

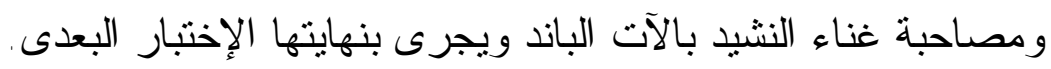




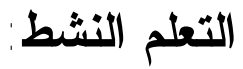

طريقة للتعليم و التعلم تجعل التلاميذ يفكرون ويتأملون فيما يتعلموه ويستمتعون به ، وينمى

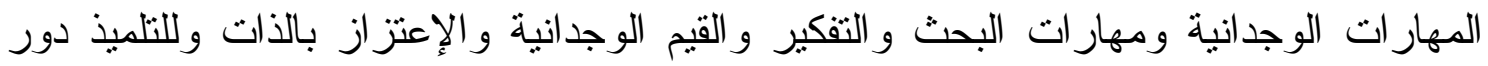

$$
\text { كبير وفعال بها. (lv:l) }
$$

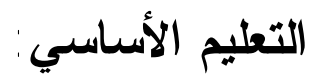

يكون في المرحلة الابتائية، تمنل هذه المرحلة أولى درجات السلم التعليمي النظامي في الدولة وتتمل الفئات العمرية من T Y T سنة، وتمتد الدراسة بها لمدة ست سنوات. وتتقسم هذه المرحلة بدور ها إلى حلقتين هما:

- الحلقة الأولى: وتضم الصفوف الثناثة الأولى من التعليم الابتدائي، ويطبق في جميع مدارسها تقريباً نظام معلم الفصل، ويقوم في ظل هذا النظام معلم واحد بتدريس معظم المو اد ماعدا اللغة لإنة الإنجليزية، التصميم، التربية الموسيقية، و التربية الرياضية.

- الحلقة الثانية: وتضم الصفوف الثلاثة العليا، ويطبق في مدارسها نظام معلم المادة، حيث يدرس كل مادة در اسية معلم متخصص ومؤهل تأهيلاً نربوياً.

وتتتمل مناهج الحلقتين الأولى و الثانية من التعليم الأساسي على مواد إلز امية مشتركة تضم:

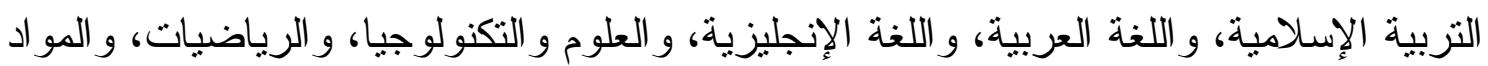

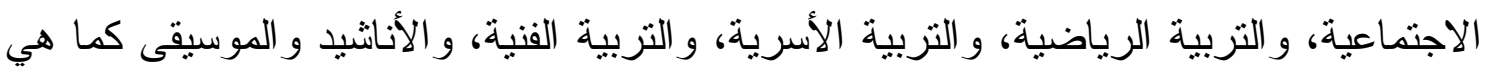

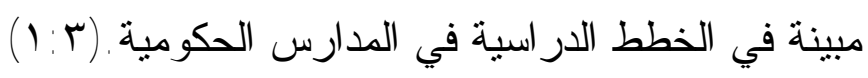

$$
\begin{aligned}
& \text { الار اسات (لسابقة: - مابة }
\end{aligned}
$$

تعددت الدر اسات و البحوث في هذا المجال ونذكر منها على سبيل المثال لا الحصر الدراسة الأولي!" تطويع بعض بنود المقررات المدرسية المختلفة فى حصة التربية الميدانية"

تهدف هذه الدراسة إلى تتمية ابتكار قصص مشوقة للأطفال و أناثيد مدرسية تخدم بعض بنود

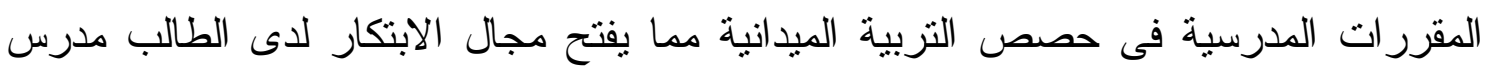


التزبية الميدانية لحصص شاملة مشوقة للأطفال، و اتبعت الدراسة المنهج الوصفى"تحليل

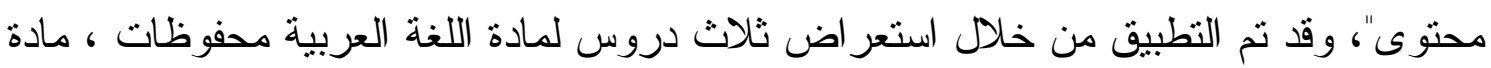
الرياضيات، ومادة الانجليزى وجاءت توصيات البحث للطالب المعلم والمشرفين على التربية الميدانية و على المناهج المدرسية للصف الذى يتم التنريس إليه و ابتكار دروس شاملة تعتمد على لئى القصص الحركية، مما يساعد علي الاهتمام برفع مستوى عزف الآلات الموسيقية وتتمية

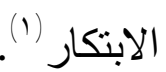

الاراسة الثانية:" أثز استخدام الألعاب الموسيقية على التحصيل لطفل " المرحلة الابتدائية

تهذف هذه الدراسة إلي معرفة أثزر استخدام القصة الحركية فى توصيل العناصر الموسيقية للطفل

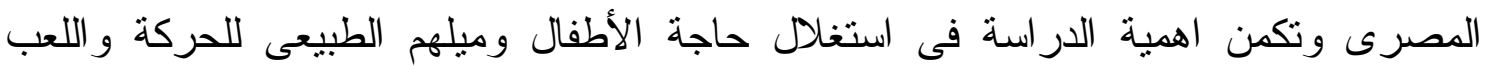
الامر الذى يؤدى إلى سرعة استيعاب المعلومة وسرعة تتفيذها، واتبعت الدر اسة منهج تجريبي مقترح لتتريس عناصر الموسيقى المختلفة لعينة من الاطفال الدارسون بمركز اثثعاع الموسيقى بكلية التربية الموسيقية مستخدمة اختبار ات قبلية وبعدية لمجموعتين تجرييية وضابطة وجاءت التوصيات ضرورة استخدام القصص الحركية المبتكرة بحصص التربية الموسيقية لما لها من

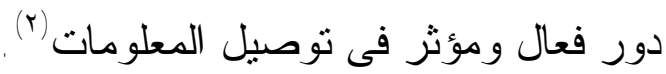

الاراسة الثالثةب" أثزر الممارسات الفنية فى تتمية القدر ات الذهنية للأطفال " تبحث هذه الدراسة الجدوى الممكنة من تطوير إمكانيات الاطفال العلمية بالاعتماد على ممارسة أهم الفنون (الرسم - الموسيقى - الفنون الحرفية الصغيرة - الإدرالك البصرى) وتتثير نتائج الدر اسة إلى إمكانية ممارسة هذه الفنون بالطريقة الاكاديمية الصحيحة لمختلف الاعمار، اضافة

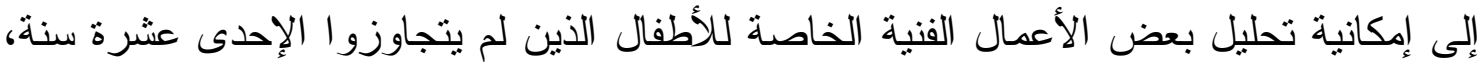
و اكتشاف مهار اتهم الفكرية و النفسية من خلال هذه الفنون، كما اهتمت أيضا بتطوير المهارات

( (1) نصر مددوح حسين: تطويع بنود المقرر ات المدرسية المختلفة في حصة التربية الميدانيــة، مجلــة علــوم

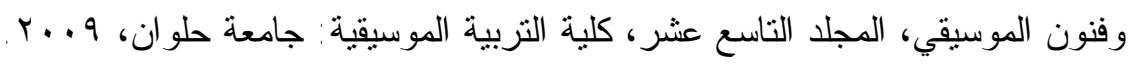

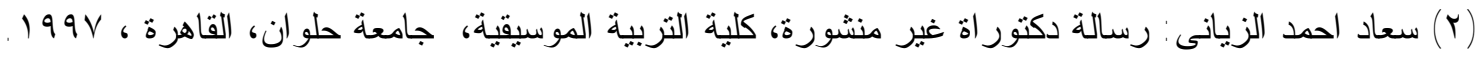

\section{مجلة علوم وفنون الموسيقى -كلية التربية الموسيقية - المجلد التاسع والثلاثون - يونيو 11.}


العقلية و العملية للاطفال ذوى الاحتياجات الخاصة، وكيفية التو اصل معهم من خلال ممارسة بعض أنو اع هذه الفنون (1).

\section{تعليق الباحثة:}

اتفق البحث الر اهن مع الدراسة الأولي في استخدام المقررات الدراسية كمادة لتتمية الابتكار ولكنها اختلفت معه في العينة حيث ان الهدف كان تتمية الابتكار و الابداع لدي الطالب المعلم

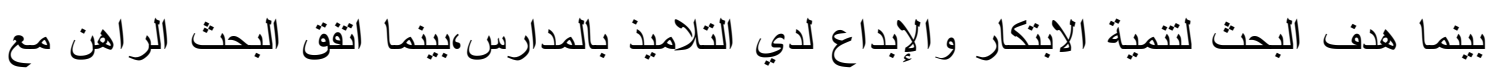
الداسة الثانية في أهمية توظيف القصة الحركية في كسر الجمود و الملل في العملية التعليمية

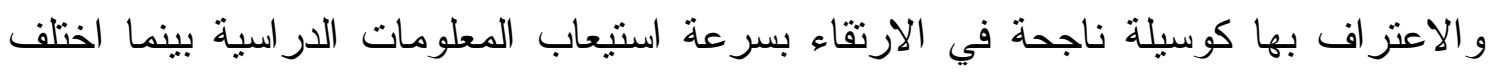

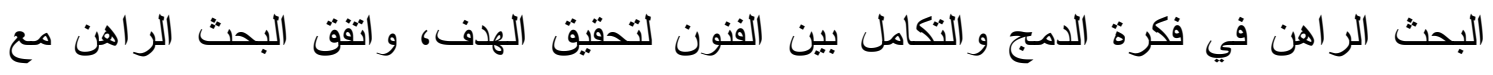
الدراسة الثالثة في فكرة الدمج بين مختلف الفنون في رفع إمكانيات الأطفال الفكرية و النفسية

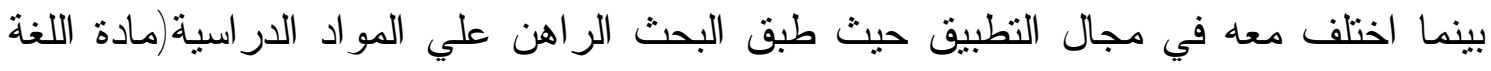
العربية) ،وجاء البحث الر اهن محققا لتوصيات الدر اسات السابقة.

$$
\text { ينقسم البحث الى: }
$$

الجانب النظرى: بشنمل على - الى

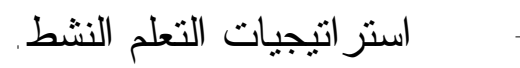

- مور المعلم و التلميذ فى التعلم النثط.

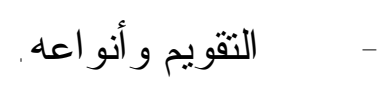

الاتجاه الحديث فى الندريس بالو لايات المتحدة الأمريكية.

الجانب التطبيقى: يشتمل على

ا - أمهيد عن ما تم بالبحث.

(1) مروان عمر ان عبد المجيد: بحث منشور، مجلة الآداب و العلوم الاجتماعية، جامعـة الـسلطان قــابوس، 
r -الخطو ات العامة لسير حصة اللغة العربية الأولى للارس قبل نوظيف مادتى الثربية الموسيقية و التربية الفنية (الحصة التقليدية). r -خطوات سير حصة التزبية الفنية فى النطبيق على دروس اللغة العربية. ع -خطو ات سير حصة التربية الموسيقية فى التطبيق على دروس اللغة العربية . ه -خطو ات سير حصة اللغة العربية الثانية للارس بعد توظيف مادتى التربية الموسيقية و النربية الفنية (الحصة الثناملة). 7 -استعر اض للثناث دروس من دروس اللغة العربية للتناث صفوف الابتدائية الأولي (العمل، ياربنا سبحانك، أسماء الاشارة) للحصص الاربعة. V - عرض نتائج الاختبار ات القبلية و البعدية لتللك الدروس إحصائيا. 1 -نموذج استطلاع رأى عن فكرة التوظيف. 9 -نتائج استطلاع ر أى المعلمين المشتركين فى التوظيف و التطبيق.

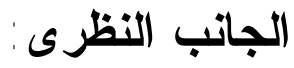
يتبع البحث أستر اتيجيات التعلم النشط فى التطبيق ويستعرضها فيما يلي : استر اتيجيات التعلم النشط: - مات 1- (العصف الذهني.

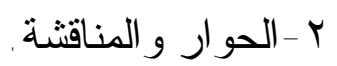

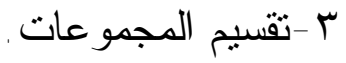

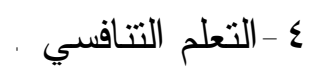

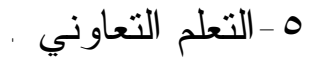

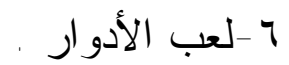

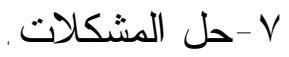

ولقد استخدمت الباحثة فى البحث الر اهن بعض من استر اتيجيات النعلم النشط منها: 
1 -العصف الذهنى: تلك العملية التى تساعد على توليد العديد من الحلول لمشكلة معينة من خلال

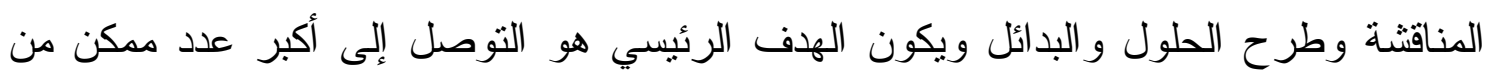
الأفكار وليس لمناقثة الآراء ونقدها.(9 (1: 1) وفى البحث الر الهن يقوم معلم التزبية الموسيقية بأداء عصف ذهنى للتناميذ فى حصة التربية الموسيقية لكيفية تتفيذ القصة الحركية على نشيد اللغة العربية من حيث اختيار الثخصيات، وكيفية الأداء.

ץ -الحوار والمناقثة: تعد من أفضل الطرق التى تضمن اثشترالك الطلاب اثتر اكا ايجابيا فى

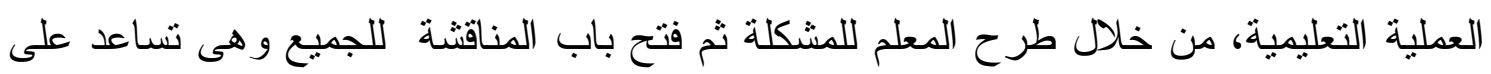

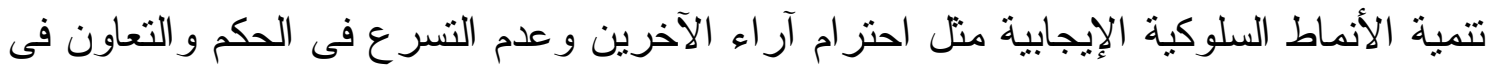

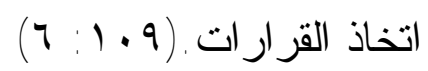

وفى البحث الراهن يقوم معلم التربية الفنية فى حصته بطرح العديد من الرسومات واجراء

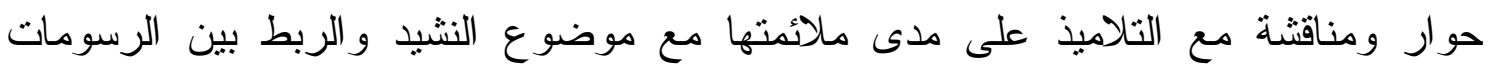
المختارة وبين أبيات الثعر الخاصة بالنشيد.

r -ثقيم المجموعات: تقسيم الفصل الى مجموعات لنطبيق الموضوع أو الفكرة التى تم

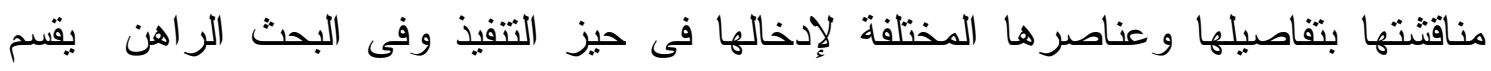
مدرس التربية الموسيقية الفصل الى مجموعات منها ما يؤدى القصة الحركية التى نم الإتفاق

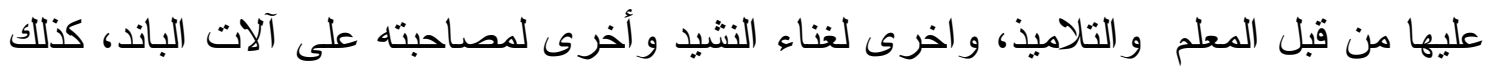
مدرس التربية الفنية حيث يقوم بتقسيم الفصل لهجموعات لتنفيذ الهجمات المطابقة لكلمات النشيد و التى تم اختيار ها بو اسطة التلاميذ .

؛ -التعلم التعاونى: يقوم به مدرس التربية الفنية فى خلق حلقات عمل تعاونى بين التلاميذ بعضهم بعضا فى أداء المجسمات الخاصة بكلمات النشيد تحت إنثر افه وتوجيهه فئه هـ ـلعب الأدوار: يقوم التلاميذ فى حصة التربية الموسيقية بتبادل الأدوار فى أداء شخصيات

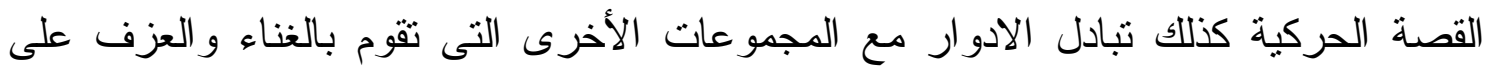

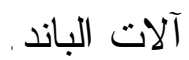


دور المعلم والتلميذ في التعلم النشط :

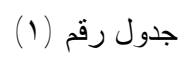

مقارنة بين دور المعلم ودور التلميذ في التعلم النشط

\begin{tabular}{|c|c|}
\hline دور التلميذ & دور المعلم \\
\hline 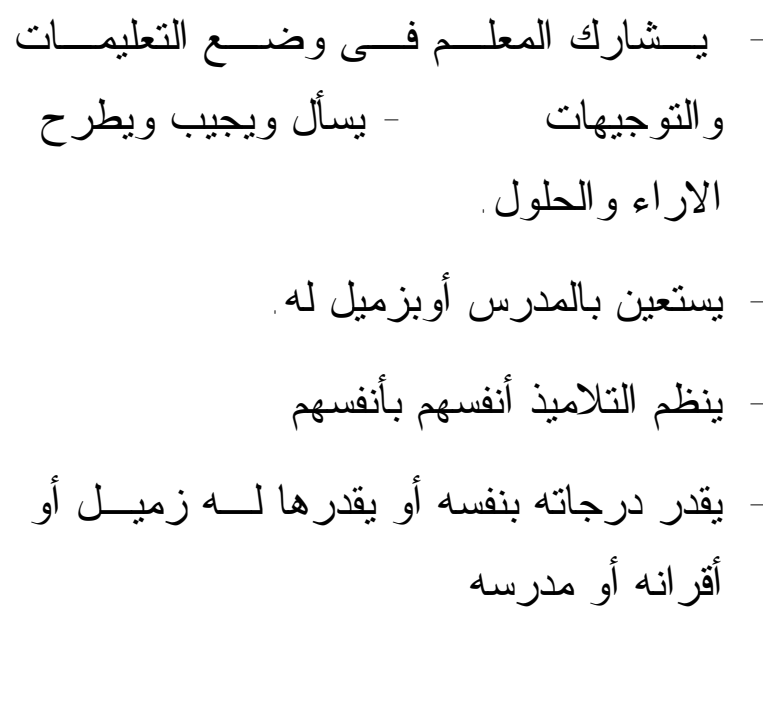 & 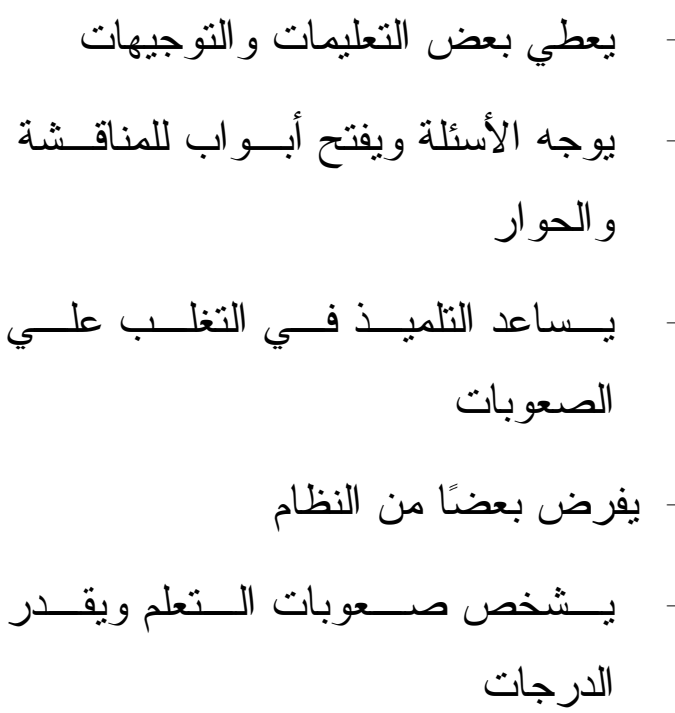 \\
\hline
\end{tabular}

ومما سبق بتضح لنا مدى فاعلية دور التلميذ فى التعلم النشط بينما يتمنل دور المعلم فى التى الإثر اف و التوجيه و التنيسير و التحفيذ كما هو بألئ دور بالبحث الر اهن.

التقويم:

هو عملية تشخيص وعلاج لموقف التعلم أو أحد جوانبه أو للمنهج ككل فى ضوء الأهداف دهن التزبوية المنشودة.

\section{أنواع التقويم :}

1 -التقويم المبئي : وهو الذي يعطى معلومات وبيانات عن مستويات التلاميذ العقلية

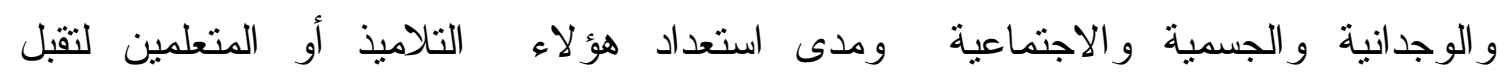

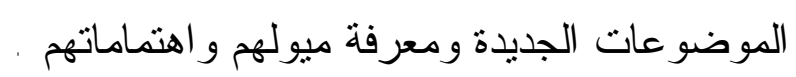
r -التقويم البنائي : هو الذي يصاحب الأداء أو التنفيذ ويهدف إلي تصحيح المسار عن طريق التتخيص و العلاج الفوري لكل ما يعترض عملية التعليم و التعلم من عقبات. 
ب -التقويم الختامي: هو أكثر أنواع التقويم شيوعا ويخدم عدة أغراض منها: - - تقدير مدي تحصيل التلاميذ ومدي تحقيقهم لأهداف المنهج .

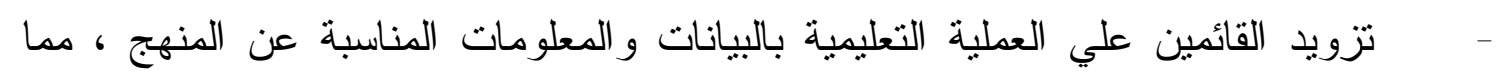

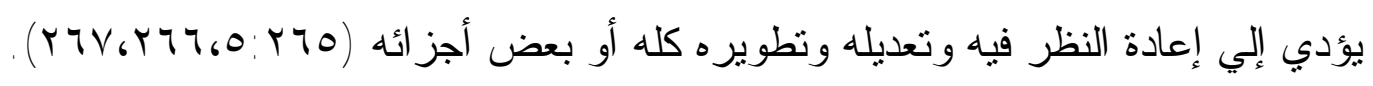

ولقد استخدم البحث الر اهن التقويم البنائى من خلال توجيهات كل من معلمى التربية الموسيقية

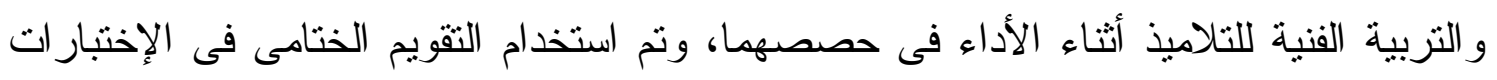

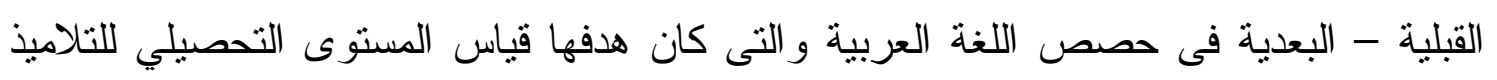
قبل وبعد النطبيق بالتزبية الموسيقية والنزبية الفنية.

\section{الاتجاه الحديث فى التدريس بالولايات المتحدة الأمريكية}

تعتبر الو لايات المتحدة الأمريكية الأكثر شيوعا في استخدام الفنون بأنو اعها فى العملية التعليمية

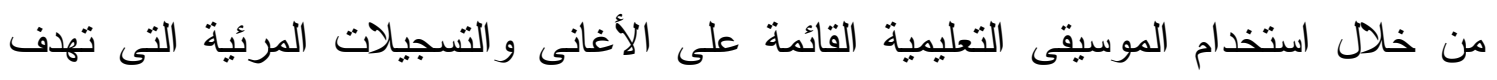

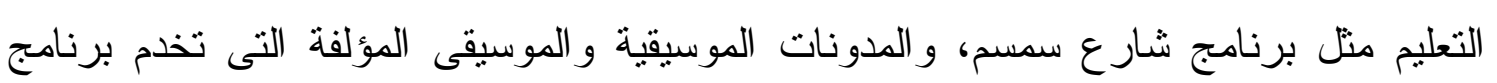

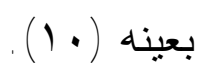

فى معظم الأحيان تضاف الموسيقى الى قصة او درس وتقدم فى صورة اغنية لاعتبار ها أسهل

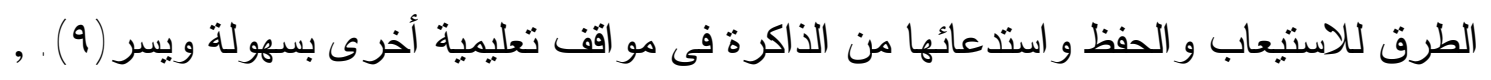

ومن المؤسسات التى تستخدم الفتون فى الولايات المتحدة الأمريكية : ا-المركز الكندى (سيتا) CETA)Kennedy Center) (تغير التعليم من خلد الفنون : (Changing Education Through The Arts يقوم بالتعاون مع ثمانية مدارس متخصصة فى الفنون بو الثنطون، يعملون معا فى تدريب فريق

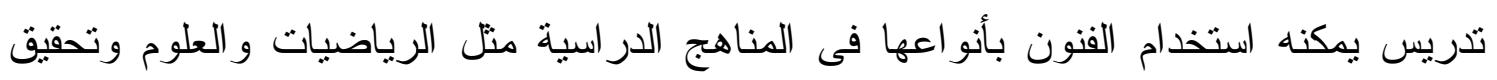

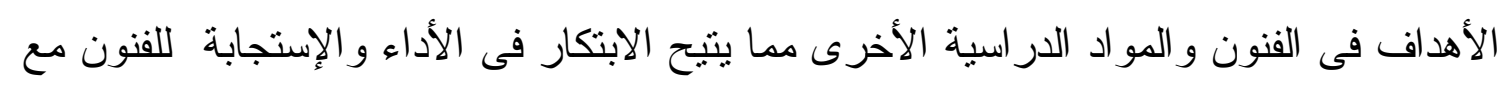
المحافظة على كيان المو اد الأخرى وسهولة استيعابها. 


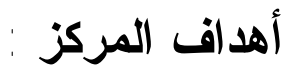

• الإيمان بالفنون وتطوير المعلومات و المهارات من قبل المعلمين من أجل استخدام توظيف

$$
\text { الفنون فى المناهج الدر اسية. }
$$

• تكوين شبكة اتصال لمعلمين المواد الأخرى فى مدارسهم مع المتخصصون فى الفنون لتدريبهم وتطوير هم المستمر فى هذا المجال . • توفير نظام دعم داخلى وخارجى للمعلمين من خلال شبكات الاتصال . • مشاركة المعلومات و الخبرات وكل ما هو جديد مع منظمات الفنون المحلية الأخرى. (^)

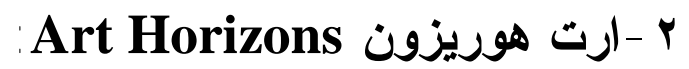

يقوم على استخدام الموسيقى كسائر الفنون فى التعليم لخدمة المدارس فى نيويورك ونيوجيرسي

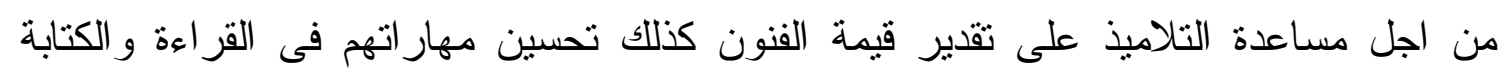

و الرياضيات. (11)

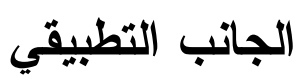

تمهيد لما تم فى هذا البحث: قامت الباحثة بما يلي:

1 - الإجتماع و التتسيق بين الثثلاث معلمين المختصين بتدريس الثثلاث مواد(التربية الموسيقية

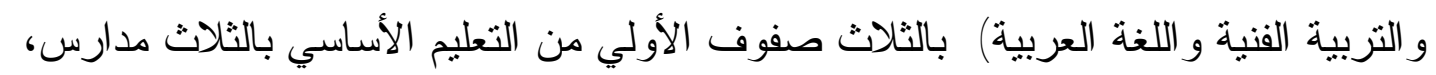

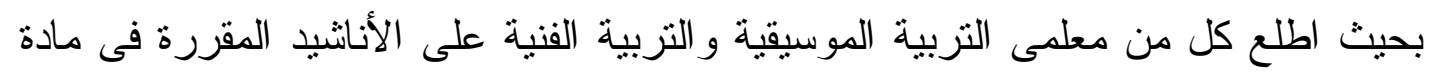
اللغة العربية ولهم حق الاستفسار و المر اجعة اللغوية من معلم اللغة العربية. ץ - تم تتسيق حصص الجدول الددرسي بحيث تلى حصة اللغة العربية الأولى لثرح الدرس

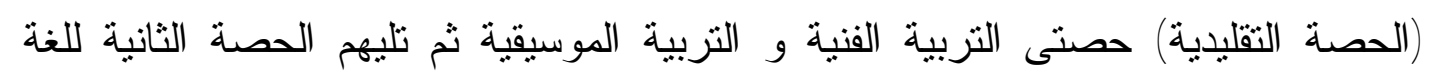
العربية للتطبيق على الدرس (الحصة الثاملة). r - الاضطلاع على اهداف كل من مادتى التربية الفنية و التربية الموسيقية الخاصة بتلك المرحلة لدمج تطبيقهما اثثاء التوظيف فى حصنى التربية الفنية و التربية الموسيقية. 
ع - نم وضع اختبارات (قبلية وبعدية) و اعطائها لمعلمين اللغة العربية بالمدارس المطبقة بها

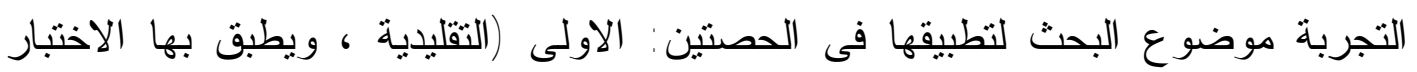

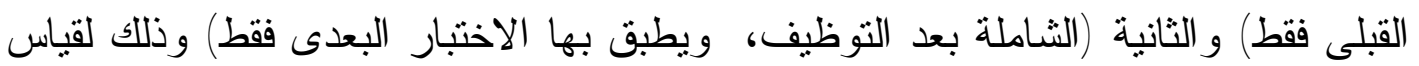

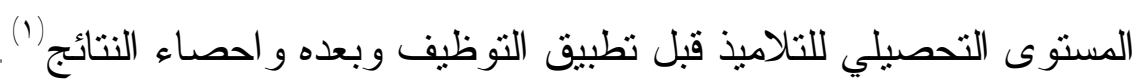
ه - الحصة الثاملة: تانى بعد الحصة التقليدية وحصنى التربية الفنية و التزبية الموسيقية التى ينم التوظيف بهما، وفى تلك الحصة يتثارك كل من معلمى التربية الفنية و التربية الموسيقية مع معلم اللغة العربية فى تطبيق الدرس بعد التوظيف باستخدام المجسمات التى تم تتفيذها

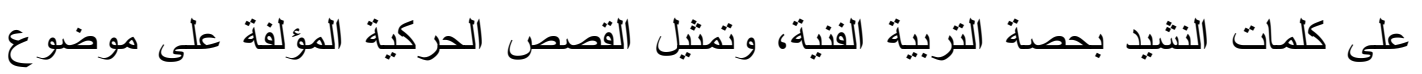
النشيد كذلك مصاحبة غناء النشيد بالات الباند و التى تم التنريب عليهما فى حصة النزبية الموسيقيية ، ثم يتم اجر اء الاختبار البعدى للفصل من قبل معلم اللغة العربية.

الخطوات العامة لسير حصة اللغة العربية الأولى للارس قبل توظيف مادتى التربية الموسيقية والتربية الفنية (الحصة التقليدية) (0 ع دقيقة): 1 - يقر أ المعلم كلمات النشيد بشكل و اضح للتلاميذ. r - يقوم المعلم بشرح النشيد بالطريقة التقليدية فى الحصة واستعر اض الكلمات اللغوية الجديدة ويجيب على اسئلة التلاميذ. r - يعيد المعلم قر اهة النشيد مع ترديد التلاميذ للنشيد ور ائه عدة مر ات. ع -يجرى المعلم أختبار قبلى لقياس المستوى التحصيلي للتناميذ. خطوات سير حصة التربية الفنية فى التطبيق على دروس اللغة العربية(ه ؛ دقيقة) ا بمهي معلم التربية الفنية للتلاميذ عن فكرة توظيف النربية الفنية لخدمة درس اللغة العربية " النشبد" التى نم در استه بالحصة السابقة. r - يقوم معلم التربية الفنية بقر اهة كلمات نشيد اللغة العربية للتلاميذ.

( (1) تم وضع نماذج الاختبار ات القبلية والبعدية من قبل مستثار اللغة العربية بوز ارة التربية والتعليم، كما قـام بمر اجعة نثيد النحو المطبق و اعتماده قبل التطبيق. 
r - يناقش المعلم التلاميذ فى المعانى المشتمل عليها النشيد من خلال طرح العديد من الصور

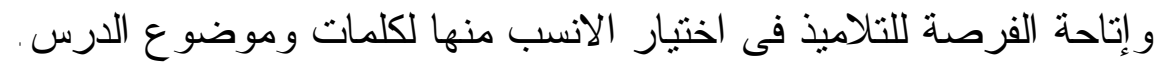
ع - يوز ع المعلم الصور المختارة من قبل التلاميذ عليهم للتلوين.

بعد الإنتهاء من التلوين يقوم المعلم بتقسيم مجموعات نتشرك مع بعضها البعض فى تتفيذ

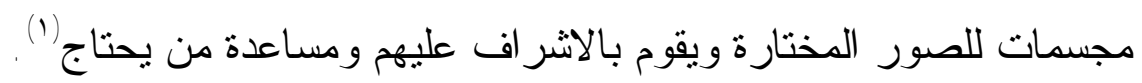

خطوات سير حصة التربية الموسيقية فى التطبيق على دروس اللغة العربية (0 د دقيقة): يذهب التناميذ إلى حصة الموسيقى بالتز امن مع الحصنتين السابقتين بنفس الاسبو ع ويقوم مدرس التربية الموسيقية بالتمهيد عن فكرة نوظيف التربية الموسيقية للنطبيق على درس اللغة العربية ثم يقوم بتطبيق مفاهيمه الموسيقية مستعين بنشيد اللغة العربية كتصفيق الوحدة المصاحبة للنشيد

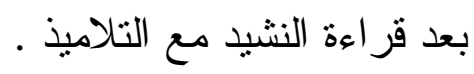
ا يقوم المعلم بأداء عصف ذهنى للتناميذ لتكوين قصة حركية مطابقة لأحداث وكلمات النشيد. r - ويتم تقسيم الفصل لثلاث مجموعات (طبقا لعدد التلاميذ بالفصل) لتقوم مجموعة بالأداء

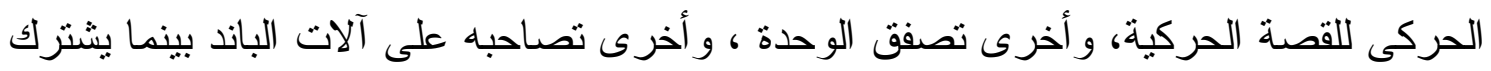
الجميع فى غناء النشيد اثثاء الاداء.

r بينت تبادل الادو ار بين المجموعات المختلفة. خطوات سير حصة اللغة العربية الثانية للارس بعد توظيف مادتى التربية الموسيقية والتربية الفنية (الحصة الثاملة) (0ء دقيقة): يعود التلاميذ لحصة اللغة العربية الحصة الثاملة ويتم

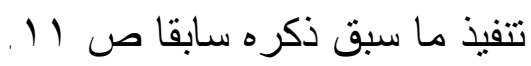

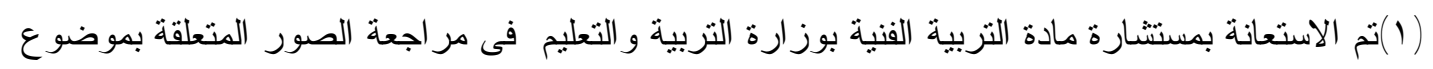

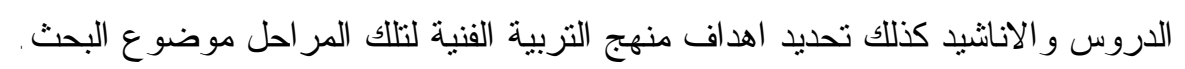
يستمع التلاميذ اثثاء التلوين و اداء المجسمات للنثيد مسجل ويغنى التلاميذ مع الثريط النثيد اثناء التلوين وتتنفيذ

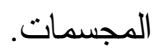
(ץ) تم الاستعانة بمستثارة التربية الموسيقية بوز ارة التربية و التعليم فى تحيد اهداف منهج التربيــة الموســيقية التلك المر احل موضوع البحث. 
استعراض للثلاث دروس من دروس اللغة العربية للثلاث صفوف الابتدائية الأولي (العمل، ياربنا سبحاتك، أسماء الإشارة): درس العمل للصف الاول الابتدائى (من الكتاب الوزارى)|لفصل الاراسي الثانى، مدرسة محمد زهران الرسمية لغات بالاسكندرية: اولا الحصة التقليدية: (يتبع المطلم خطوات سبرات لريز الحصة السابق ذكرها) كلمات النشيد الإختبار القبلى: ا -رتب الكلمات الآتية لتكون جملة مفيدة

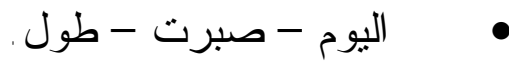

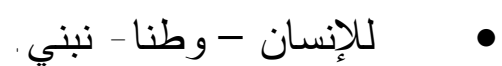

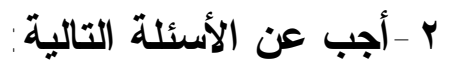

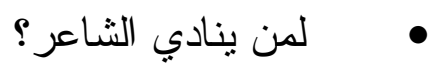

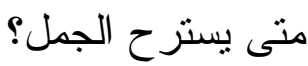

ثانيا التوظيف فى حصة التربية الفنية:(يتبع المعلم خطوات سير الحصة السابق ذكرها)

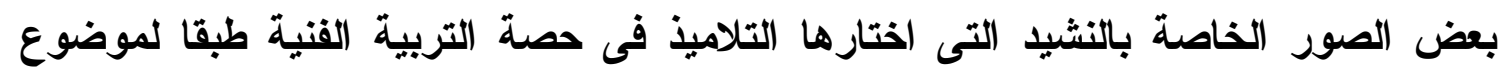
وكلمات الدرس الن
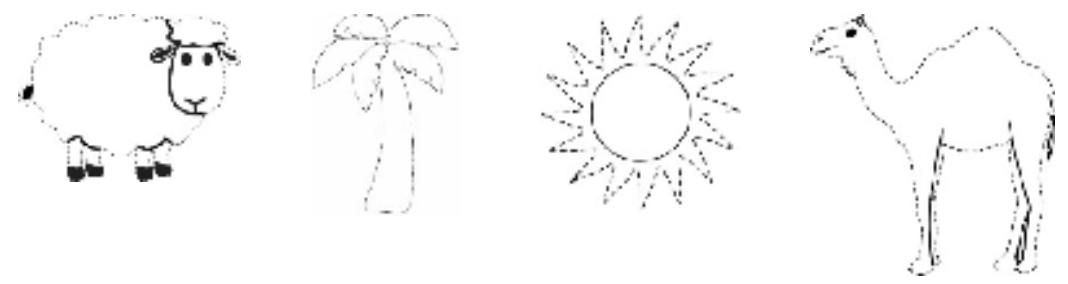

شكل رقم

نماذج من بعض الصور الخاصة بكلمات نشيد العمل بمادة اللغة العربية للصف الاول الابتدائي 


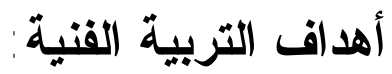

تتشيط الحواس البصرية من خلال العناصر الجمالية بالبيئة الحيطة، تضمين للعناصر ومفردات زخرفية تنمي الحواس الادر اكية، يقدر قيمة البيئة ودورها في اثراء العمل العية الفني.

ثالثا التوظيف فى حصة التربية الموسيقية : (يتبع المعلم خطوات سير الحصة

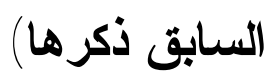

القصة الحركية الخاصة به المعدة من قبل التلاميذ:

يوجه المعلم التلاميذ فى العصف الذهنى لبعض المهن كمهنة رعى الغنم التى كانت مهنة (رسول

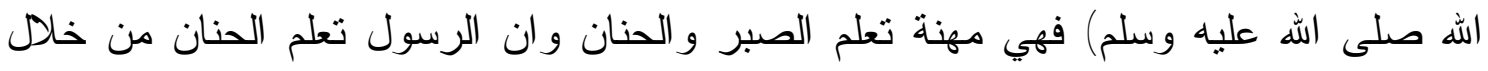
مهنة رعى الغنم وان العمل فى حد ذانه شرف. يقوم المعلم بتوزيع الأدوار على التلاميذ شخصية (الجمل)، ثلاث تلاميذ (نبات الصبار)، أربع تلاميذ (النخيل)، تلميذان (الخروف)،

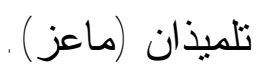

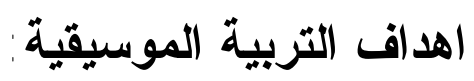
الأداء البطيء (حركة الجمل)، الأداء السريع (حركة الخراف والماعز ). رابعا الحصة الثاملة: بعد الاداء الجماعى يجرى الإختبار البدى:

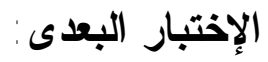
ا - اتب الكلمات الآتية لتكون جملة مفيدة

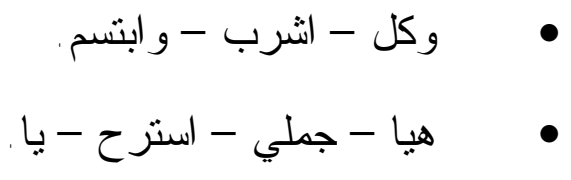

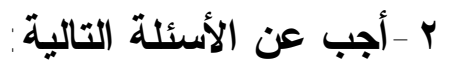

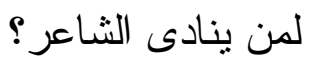


درس ياربنا سبحاتك للصف الثانى الابتدائى (من الكتاب الوزارى) الفصل الدراسي الثانى مدرسة السلام الرسمية للغات بالاسماعلية

اولا الحصة التقليدية:(يتبع المعلم خطوات سبر الحصة السابق ذكرها) كلمات النشيد

يا خالق الأكوان ل لخدمة الإنسان

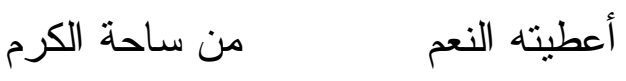
و هبته العيون وفوقها الجفون و الوجه و الخدين و الأنف و الأننين وقوة البنيان و الفم والأسنان

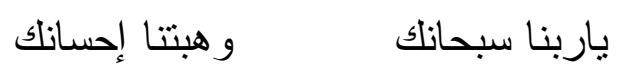
الاختبار القبلى: - - القى ا -رتب الكلمات الآتية لتكون جملة مفيدة الأكوان - الله - خالق الله - الإنسان - نعما - وهب - كثيرة r - أجب عن الأسئلة التالية:

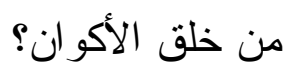
ما نعم الله علينا؟ 
ثثانيا التوظيف فى حصة التربية الفنية: (يتبع المعلم خطوات سير الحصة السابق ذكرها) نماذج من بعض الصور الخاصة بالنشيد التى اختارها التلاميذ فى حصة التربية

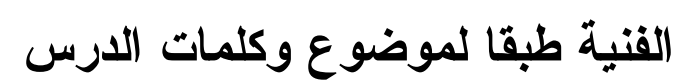

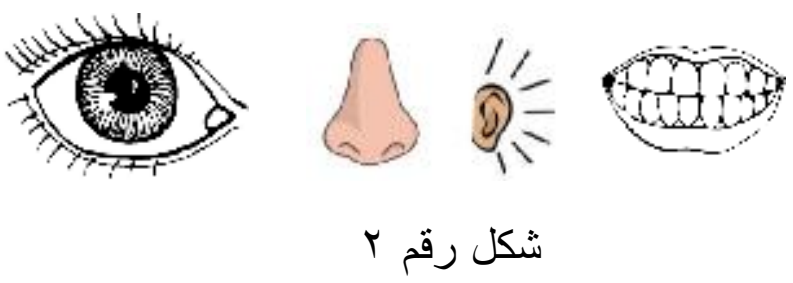

نموذج من الصور الخاصة بكلمات نشيد ياربنا سبحانك للصف الثانى الابتائي

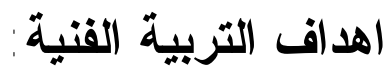

يدرك جماليات العناصر النباتية والكونية الدختلفة، وما تحتويه على عناصر زخرفية، يدرك الفرق بين الدرجات اللونية المختلفة، يفرق بين الخصائص وبين الانثكال و الألوان. ثالثا التوظيف فى حصة التربية الموسيقية : (يتبع المعلم خطوات سير الحصة (السابق ذكرها) القصة الحركية الخاصة به المعدة من قبل التلاميذ: شخصيات الأداء تلميذ بحمل لافتة (الثمس)، تلميذ يحمل لافتة (القمر)، تلميذ يحمل لافتة (النجوم)، تلميذ يحمل

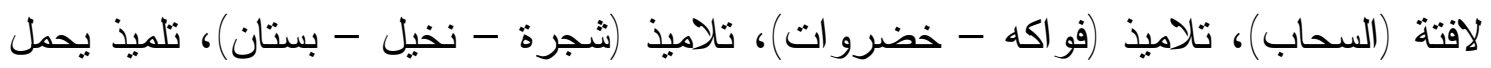

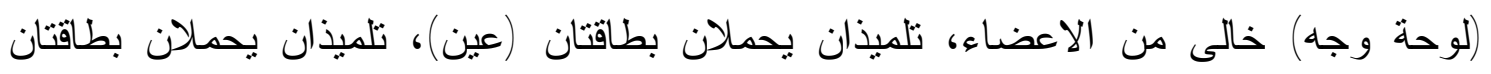

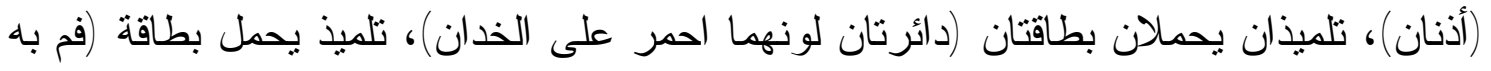

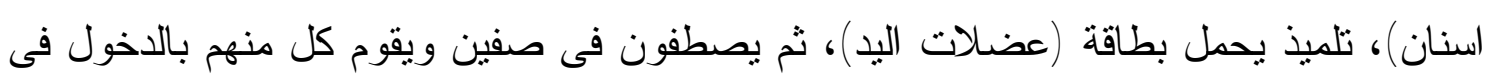
دورة مع غناء كلمات النثيد.

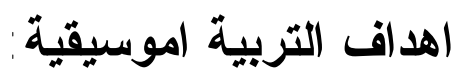
استنباط إيقاع مصاحب للحن، مصاحبة الغناء بآلات الباند، تصفيق الوحدة. 
رابعا الحصة الثاملة: بعد الاداء الجماعى يجرى الإختبار البعدى: الإختبار البعدى: - n

ا -رتب الكلمات الآتية لتكون جملة مفيدة • • ل النا - الله - النعم - أعطى. الله - الإنسان - وهب - البنيان - قوة.

r - ب أجب عن الأسئلة التالية:

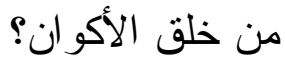
ماذا وهب اله للإنسان؟

القاعدة اللغوية (اسماء الاشارة) للصف الثالث الابتدائىالفصل الدراسي الثانى مدرسة اسيوط الرسمية(اعداد الباحثة)،(يتبع المعلم خطوات سير الحصة السابق ذكرها) اولا الحصة التقليدية:كلمات النشبا هذان ،هاتان ، هؤلاء أسماء الإشارة هذا، هذه يكمن بعيدا غير هؤلاء تكتب للقريب أما الذى "أولئك طلبة مجتهدون" نكتب له ذللك ، تللك ، أو لئك

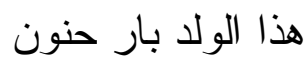
هذه الفتاة الجميلة جدا فيما عدا هذان وهاتان أسماء الإثارة تبنى دوما بالياء و أيضا بها تتصبان ترفعان بالألف وتجر ان مرفوع بالألف وينصب بالياء هذا لان مأنى المثنى هو درسنا اليوم يا أولاد ويأتى مجرور ا بالياء و هذا 


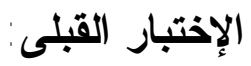

1 -استخرج اسماء الاشارة مما ياتى

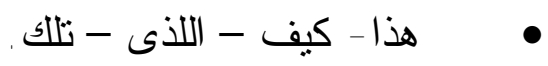

هؤلاء - أنت - هذه - هاتان - ماذا

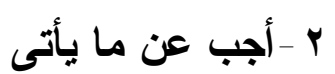
• اذكر اسماء الاثارة للقريب اذكر اسماء الاشارة للبعيد

ثانيا التوظيف فى حصة التربية القنية:(يتبع المعلم خطوات سير الحصة السابق ذكرها) نماذج من بعض الصور الخاصة بالنشيد التى اختارها التلاميذ فى حصة التربية القنية طبقا لموضوع وكلمات الارس ندس
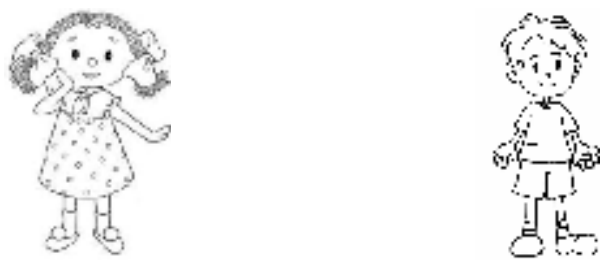

$$
\text { شكل رقم }
$$

نماذج من الصور الخاصة بكلمات نشيد اسماء الاشارة بمادة اللغة العربية للصف الثالث الاب

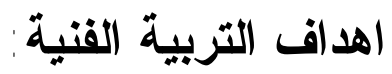

يدرك الفرق بين المجموعات اللونية المختلفة، يفرق بين الدرجات اللونية المختلفة، يفرق بين الخصائص وبين الاشكال و الألوان. 
ثالثا التوظيف فى حصة التربية الموسيقية:)،(يتبع المعلم خطوات سبر الحصة

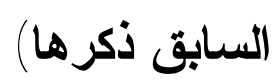
القصة الحركية الخاصة به المعدة من قبل التلاميذ: شخصيات الأداء يقوم المعلم بنوزيع الأدوار على التلاميذ بترتيب ظهورها في النشيد (أداء جماعي للقصة

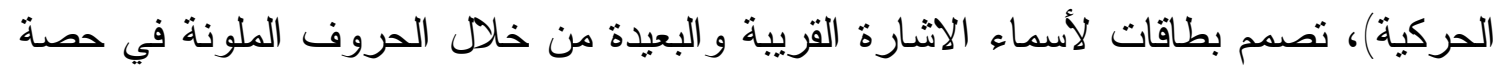

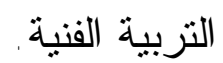

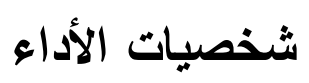

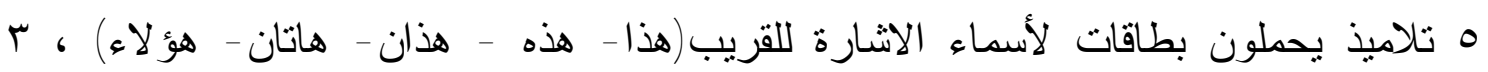

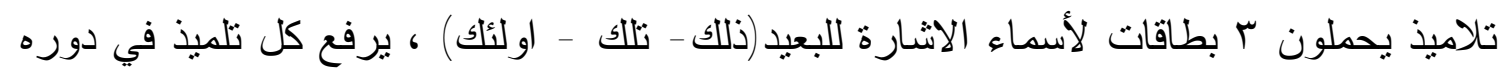

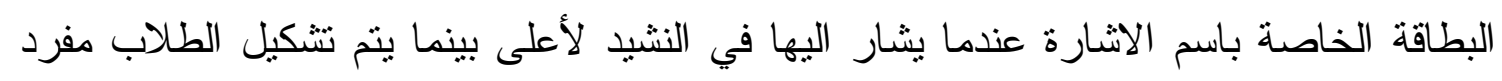

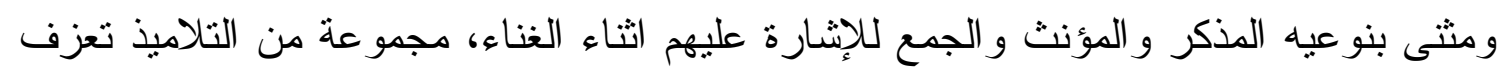
على آلات الباند أثناء الغناء ، باقي التلاميذ يصاحبون غناء الثاء النثيد بالتصفيق مع الوحدة.

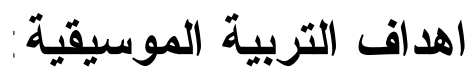
استتباط الوحدة الموسيقية الخاصة بالنثيد، التنريب على الغناء الجماعى. رابعا العصة الثاملة: بعد الاداء الجماعى يجرى الإختبار البعدى:(يتبع المطلم خطوات سير الحصة السابق ذكرها) الإختبار البعدى: استخرج اسماء الاشارة مما ياتى

$$
\text { هذان - لعل - ذلك - اولنك. - أنتم - هن - هذه - نلك - منى }
$$

ضع صح أم خطأ لكل مما يأتى بين القوسين

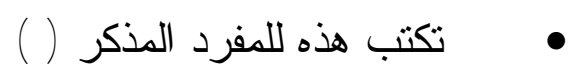

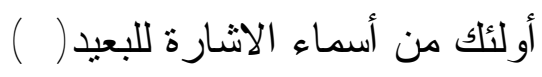


عرض نتائج الاختبارات القبلية والبعدية لتكك الاروس إحصائيا الخطة الاحصائية المستخدمة

$$
\text { 1 - الاحصاء الوصفى }
$$

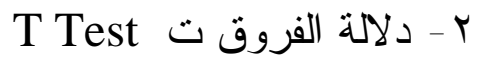

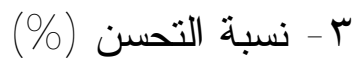

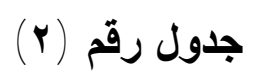

المتوسط الحسابي والاحمراف المعيارى ومعامل الالتواء

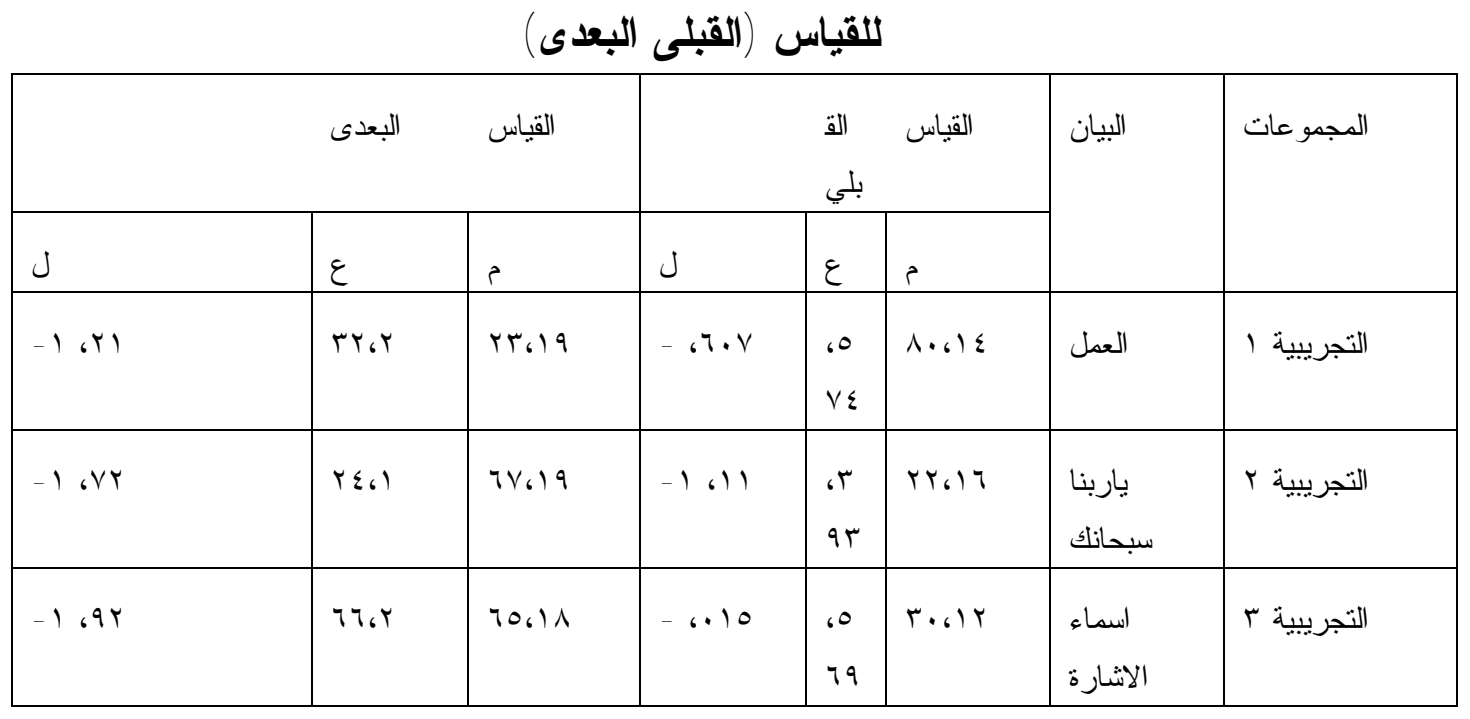

يتضح من جدول رقم (r) - (r) - (1)

تفاوتت قيم الدنوسطات الحسابية للاستجابات الفنية على الاختبار التحصيلي للغة العربية فى القياسين (القبلى البعدى)

انحصر معامل الالتو اء للقياسات (القبلية و البعدية) ما بين ( + ، - ؟ ) مما يدل على

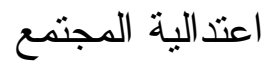


جدول رقم (r)

الفروق بين القياسين (القبلى - البعدى) ونسبة التحسن لاى كل مجموعة

\begin{tabular}{|c|c|c|c|c|c|c|c|}
\hline \multirow[t]{2}{*}{$\%$} & \multirow[t]{2}{*}{ الدلالة } & \multirow[t]{2}{*}{$ت$} & \multicolumn{2}{|c|}{ القياس البعدي } & \multicolumn{2}{|c|}{ القياس القبلي } & \multirow[t]{2}{*}{ |المجموعات | } \\
\hline & & & $\varepsilon$ & b & $\varepsilon$ & b & \\
\hline$r \cdot$. & ، & * & MrG & Pr. 19 & $V \leqslant<0$ & $1.61 \varepsilon$ & |التجريبية | \\
\hline $1, r 4$ & ‘ & $* . \mu_{6} 0$ & $r \varepsilon, l$ & $7 V 619$ & qr.r & Yr.1T & التجريبيةr \\
\hline 7.01 & $\ldots$ & $*_{\text {. I } 6 V}$ & 97.4 & 90,11 & 79.0 & $r .61 r$ & |لتجريبية r | \\
\hline
\end{tabular}

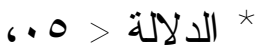

يتضح من جدول رقم (r) يوجد فروق ذات دلالة احصائية بين القياسين من كل مجموعة لصالح القياس البعدى ,تفاوتت نسبة التحسن لكل مجموعة قيد الدراسة حيث جاء اعلى نسبة تحسن لدى

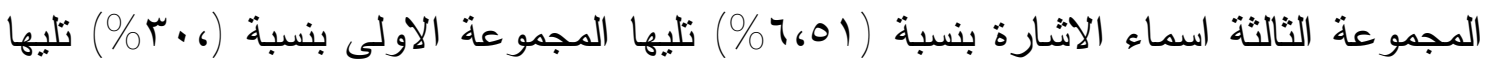
المجموعة الثانية بنسبة (Tr، 1\%)

أسماء أعضاء اللجنة المشرفة علي إستبيان إستطلاع رأي المعلمين المشتركين في التوظيف : 1 - د. احمد سعيد شلبي (مستشار اللغة العربية بوزارة التربية و التعليم) r - د. وفاء عبد السلام (مستثار النربية الموسيقية بوز ارة النزبية و التعليم) r - د. رباب عبد المحسن (مستثار التزبية الفنية بوزارة التربية و التعليم)

نتائج استبيان لاستطلاع راى المعلمين المشتركين فى التوظيف

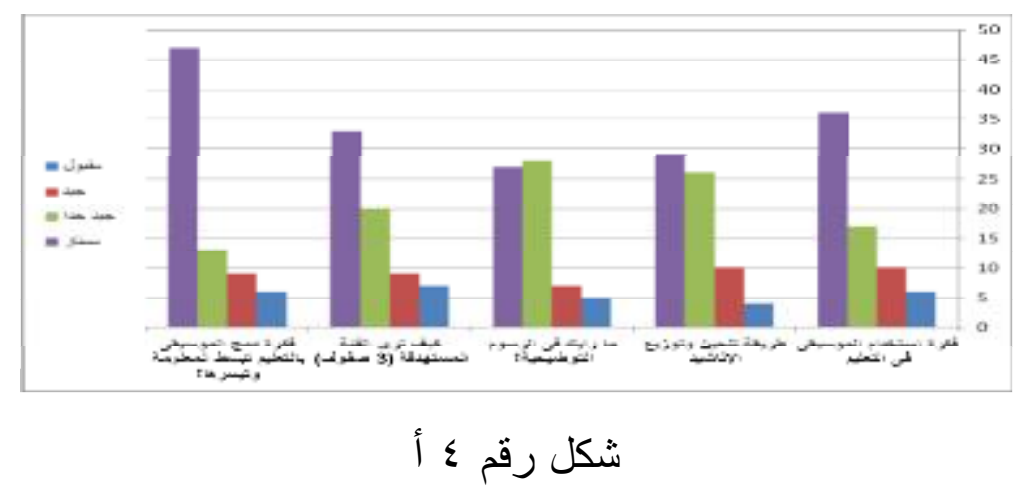

نتائج استطلاع راى المعلمين المشتركين فى التوظيف 


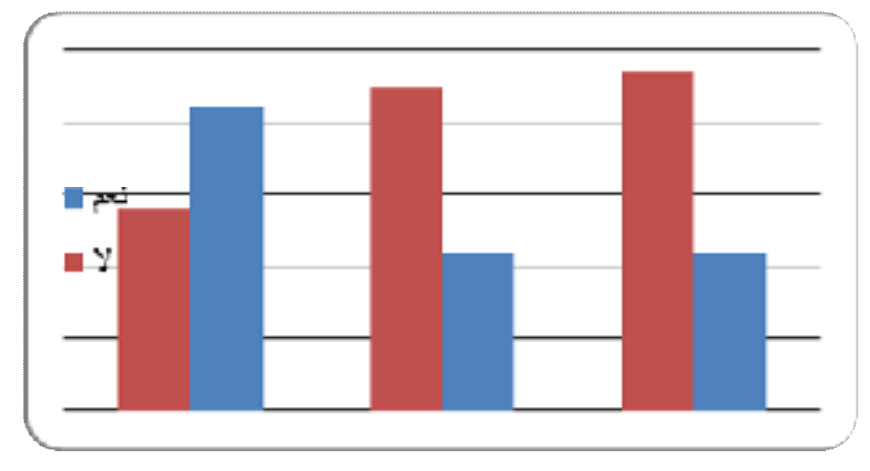

$$
\text { شكل رقم ع ب }
$$

نتائج استطلاع راى المعلمين المشتركين فى التوظيف

\section{نتائج البحث:}

من النتائج السابقة ظهر مدى تاثثر توظيف مادتى التربية الموسيقية و التربية الفنية فى التطبيق على مادة اللغة العربية فى ارتفاع المستوى التحصيلى لتلاميذ الثناث صفوف الاول الابتدائى كما ان استخدام اسلوب التعلم النشط مع التلاميذ قد ادى الى تتمية الابداع والابتكار وتقدير ار اء الاخرين وتعلم التعاون و المشاركة الايجابية بينهم .

\section{توصيات البحث:}

توصى الباحثة بضرورة الاهتمام بفكرة التكامل بين المواد الدراسية بعضها البعض من خلا التوظيف مع التزكيز على المو اد الفنية كمادة التربية الموسيقية والتربية الفنية فى التطبيق على المو اد الدراسية الاخرى لما تتسم به من مهار ات وتقنيات يمكن توضيح وتبسيط بها المعلومات وتسهيل استيعابها و امكانية الاداء الجماعى و التفاعلى بها . • تعميم فكرة البحث على السنوات الاخرى من المرحلة الابتذائية. تعميم فكرة البحث على المو اد الدر اسية الاخرى 
المدونات الموسيقية الخاصة بالثلاث أناشيد

$$
\text { نشيد "هيا إسترح يا جملي" }
$$

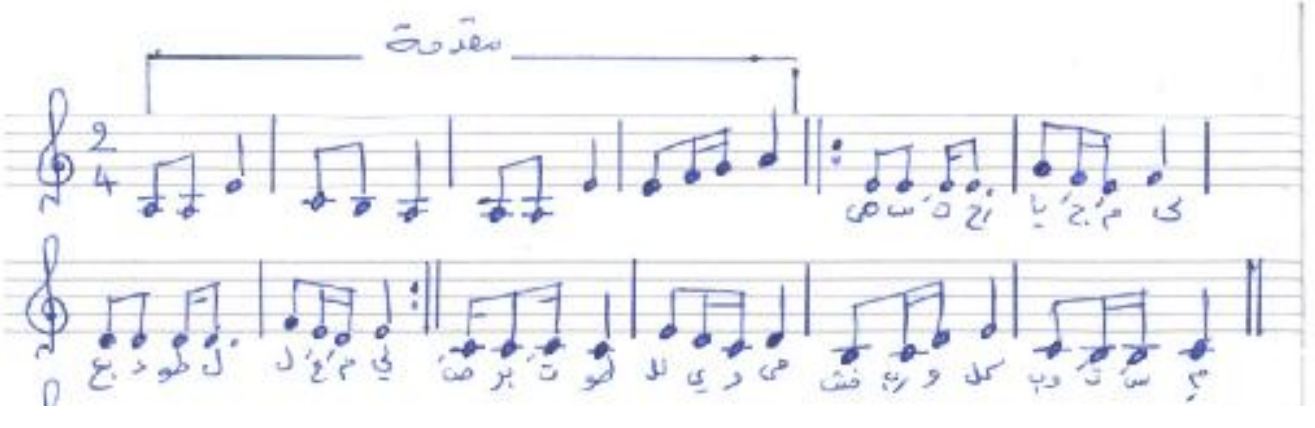

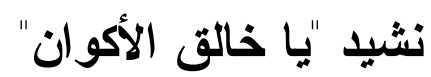

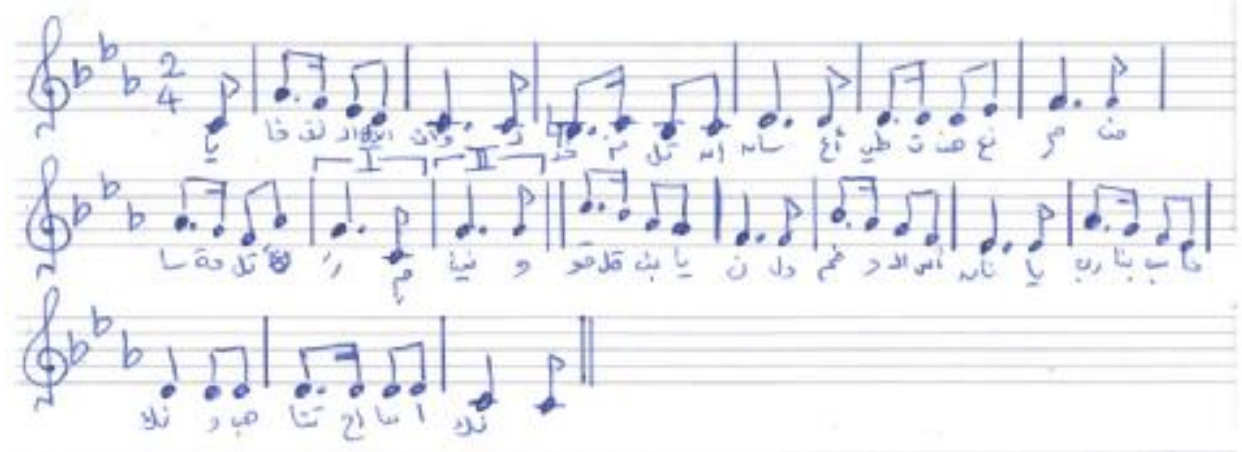

نشيا "أسماء الإشاره"

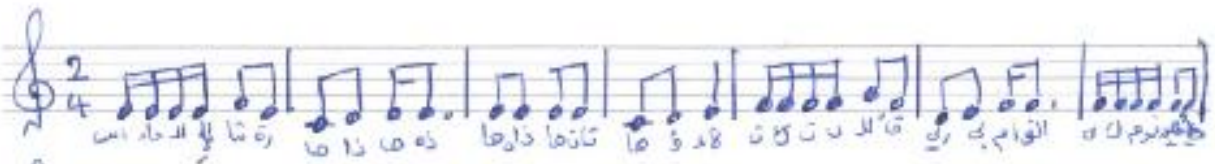
6.

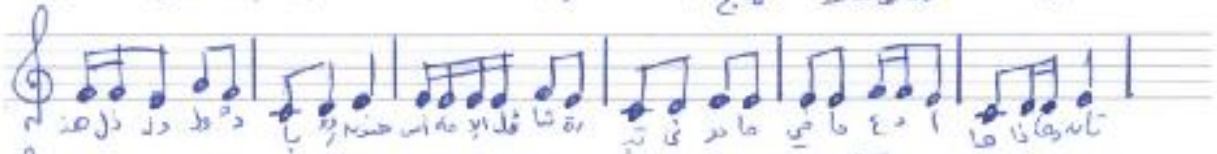

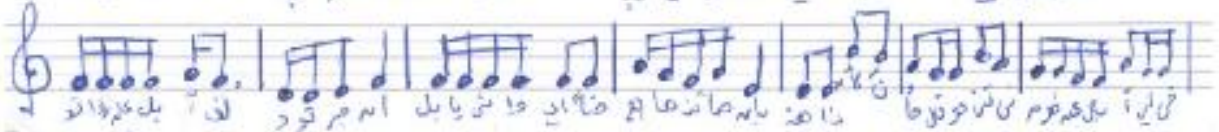
Q 
نموذج استطلاع راى معلمين الثلاث مواد(التربية الموسيقية، التربية الفنية واللغة العربية) المشتركين فى فكرة التوظيف

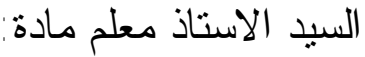

انطلاقا من اهمية التقييم و المتابعة لكل عمل، برجى من سيادتكم التكرم بالاطلاع على الاسنبيان التالى الخاص بفكرة نوظيف مادتى التربية الموسيقية والفنية للنطبيق على مادة اللغة العربية، و الاجابة على تلأك الاسئلة.

1 - نوضيح الر اى فى الموضوعات التالية بوضع علامة ـ امام احدى الثقديرات

\begin{tabular}{|c|c|c|c|c|c|}
\hline ممتاز & 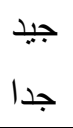 & جيد & مقبول & 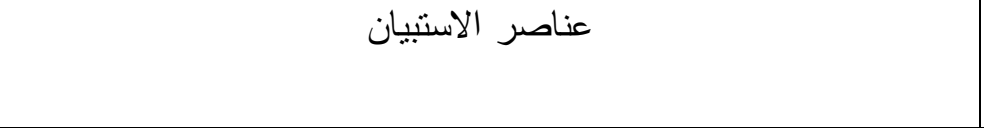 & s \\
\hline & & & & نظرك ترى فكرة استخدام الموسيقى و اللتربية الفنية فى التعليم من وجهة & 1 \\
\hline & & & & كيف ترى طريقة تلحين وتوزيع الاناثيد المختارة & $r$ \\
\hline & & & & ما ما ما ما ر ايكك في الرسوم التوضيحية و التى تم تصميمها & r \\
\hline & & & & كيف الابتدائية كيف ترى الفئة المستهدفة الثلاث صفوف الاولى من المرحلة & $\varepsilon$ \\
\hline & & & & فكرة استخدام الموسيقى و اللتربية الفنية فى التطبيق على اللغة العربية & 0 \\
\hline
\end{tabular}

r - هل لديك فكرة مسبقة عن توظيف التربية الموسيقية و التربية الفنبة بالتطبيق على اللغة العربية وهل قرأت عن اى من التجارب فى هذا الثنان؟

ע

r - اذا كانت اجابتك عن السؤ ال السابق بالايجاب نعم فاين توجد هذه التجربة وما تقييمك لها

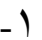

ع - هل تزى ان هناك اية مقترحات يمكن ان تساهم بشكل افضل فى تتفيذ فكرة التوظيف؟ 
0 - اذا كانت اجابتك عن السؤ ال السابق بالايجاب نعم فما اهم المقترحات التى نزى اضافتها

7 - هل نزى ان هناك تحديات او صعوبات قد نو اجه تتفيذ الفكرة

لاه

نعم $\square$ 


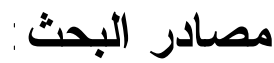

1 -احمد اللقانى على الجمل: معجم المصطلحات التربوية المعرفة في مناهج وطرق التدريس،

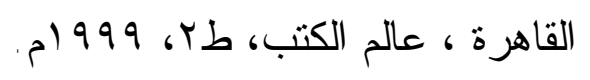

r -احمد بن محمد الفاضل: الناشطات المدرسية ماهيتها و اهيتها ومجالاتها ،كلية التزبية، جامعة

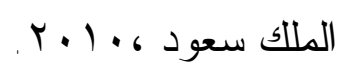

r -احمد سعيد شلبي : مشاكل التعليم فى مصر، ورقة عمل، وز ارة التربية و التعليه، 10 ـــ. ع -أميرة سيد فرج، سوزان عبداله، منال محمد على:"الانشطة الموسيقية بين النظرية

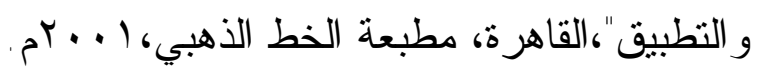

ه -على مدكور : مناهج التربية اسسها وتطبيقاتها، دار الفكر العربي، القاهرة ، 1...

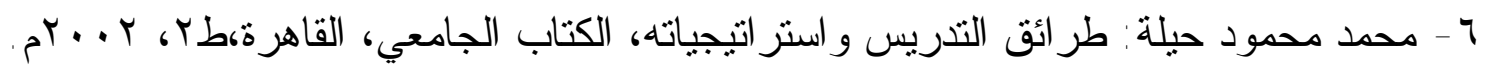
V -هدية محمد دندر اوى: برنامج مقتر حلتوظيف بعض المو اد الدر اسية لحصة التربية الموسيقية

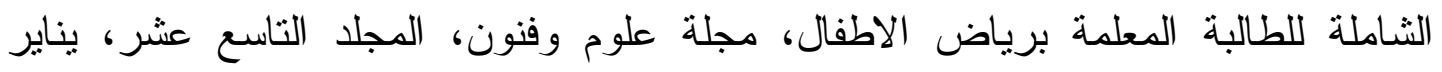

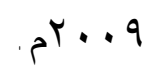

8- Changing Education Through the Art Program, The Kennedy Center and Schools.

9- https://www.songsforteaching.com/references.htm ,"How Music Promotes Learning ,Songs For Teaching".

10- https://www.thriftbooks.com/a/twin-sisters-productions/505931 "The Power of Music, Twins Sisters Production".

11- https://artshorizons.wordpress.com, "Who Are WE, Arts Horizons". 


\section{ملخص البحث}

اثر توظيف مادتي التربية الموسيقية والتربية القنية فى التطبيق على مادة اللغة العربية للثلاث صفوف الاول الابتدائية فى النهوض بالمستوى التعليمي والتحصيلي للتلميذ

مقدمة:

يلعب التعليم الدور الاساسي في بناء شخصية الإنسان و النهوض به ، و التركيز على التعلم النشط

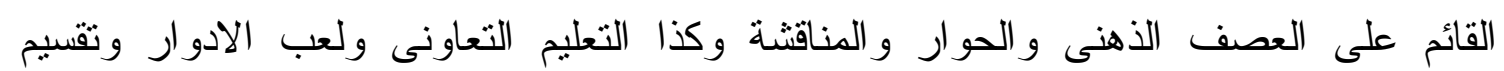
المجموعات، يؤدى الى استخدام العديد من الحواس التى توصل المعلومة بشكل مئع وشيق ولثيق

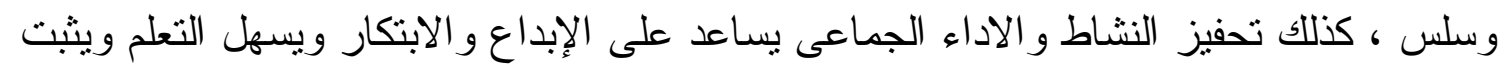

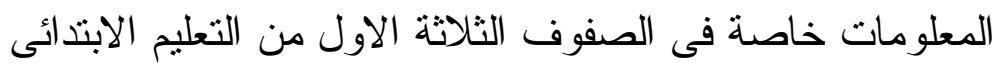

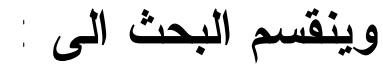

الجاتب نظرى: يشنمل على استراتيجيات التعلم النشط، دور المعلم والتلميذ فى النعلم النشط، انو اع التقويم، الاتجاه الحديث فى التنريس بالو لايات المتحدة الامريكية.

الجاتب التطبيقى خطوات التطبيق لحصة اللغة العربية للثلاث الصفوف الاول الإبتدائى قبل وبعد التوظيف، خطوات التطبيق لحصة نوظيف مادة التربية الفنية ، خطوات التطبيق لحصة

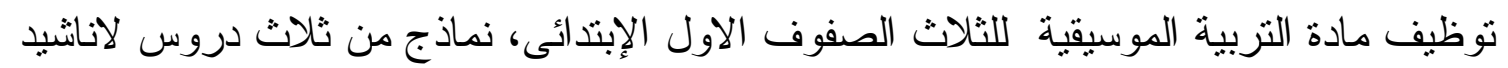
اللغة العربية (نثيد العمل، شيد باربنا سبحانك، وقاعدة لغوية "أسماء الإثارة") شاملة الكلمات

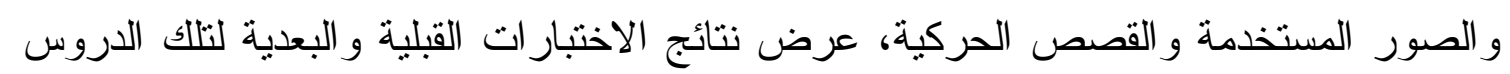

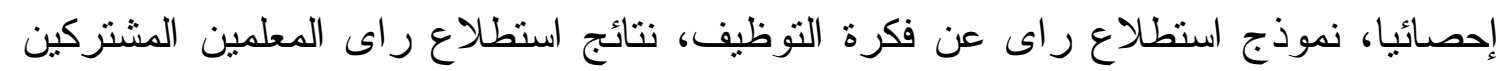

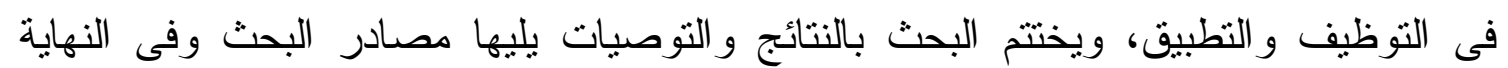
ملخص البحث. 


\section{Research Summary}

\section{The effect of applying some of the Art subjects in raising the achievement of students in the Arabic subject for the first three basic education years}

\section{Introduction}

Education plays a key role in building and promoting the personality of the human being, focusing on active learning based on brainstorming, dialogue and discussion as well as collaborative learning, role play and group division, which leads to the use of many senses that deliver information in a fun and smooth way. Creativity, innovation, facilitate learning and confirm information especially in the first three grades of primary education, the research is divided into:

Theoretical perspective: includes active learning strategies, the role of teacher and student in active learning, calendar types, the modern trend in teaching in the United States of America.

Application perspective: The application process for the share of the Arabic language for the first three primary grades before and after recruitment, the application steps for the employment share of art education, the application steps for the employment share of the musical education material for the first three primary grades, examples of three lessons for the Arabic songs, And the base of the language "names of the signal") including words and images used and motor stories, the presentation of the results of the tribal and remote tests of those lessons statistically, a form of survey on the idea of employment, results of the survey of the opinion of teachers involved in recruitment and application, he opinion questionnaire on the idea of employment, the results of the opinion survey of teachers involved in recruitment and application. The results and recommendations are followed by the research sources and in the end the research summary. 